\title{
CAG Research Committee Report: Another Stellar Year for Canadian Gastrointestinal Research
}

\author{
Derek M McKay, PhD \\ Chair, CAG Research Committee
}

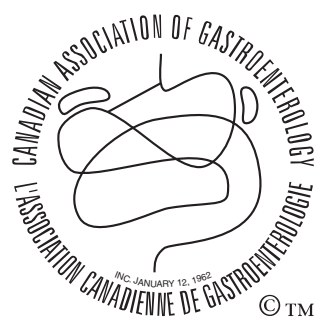

En français voir page 353

$\mathrm{T}^{\mathrm{h}}$ he goal of the Research Committee is to build, in collaboration with the Canadian Institutes of Health Research (CIHR) and the Canadian Association of Gastroenterology (CAG) partners, Canadian capacity and expertise in the discipline of gastroenterology and nutrition, and to promote excellence in research. As chair of the CAG Research Committee, it is my privilege to update the CAG membership and The Canadian Journal of Gastroenterology readership on the activities of the CAG Research Committee (2003-2004), in what has been yet another outstanding year for investment in gastrointestinal (GI) research in Canada.

First, I gratefully acknowledge the efforts of the Research Committee (Table 1), Mr Paul Sinclair, the CAG National Executive Director, and Ms Sandra Daniels, Manager of CAG, for their participation in, and commitment to, the research activities of the CAG. They all make my 'job' much easier. I take this opportunity to thank Drs A Buchan (University of British Columbia), JF Beaulieu (Sherbrooke University), K Chadee (McGill University) and W Paterson (Queen's University) who completed their terms as committee members (2000-2003), and to welcome Drs Alison FoxRobichaud, Linda Rabeneck, Natalie Rivard and Andre Buret as new committee members effective February 2004.

Details relating to eligibility and application processes for all of the following awards are available at the CAG Web site $<$ www.cag-acg.org $>$. The review and assessment of applications complies with CIHR standards and guidelines.

\section{Operating grants}

The Canadian Digestive Health Foundation (CDHF)/CAG New Investigator Grant in partnership with ALTANA Pharma Inc and the CIHR was awarded to Mark Ropeleski (MD) (Queen's University) for a project relating to IL-11 signalling in gut epithelium. The CDHF/CAG Operating Grant, in partnership with Abbott Laboratories Ltd and CIHR, went to Herbert Giasano (MD, PhD) (University of Toronto) to assess SNARE protein involvement in muscle contractility. Five applications were reviewed in each grant competition.

Fellow-to-Faculty Transition Award

Two fellows received bridge funding to facilitate a move into full-time faculty Assistant Professorships (Table 2). Dr Emma Ambrose $(\mathrm{PhD})$ will examine the role of gut pathogens in inflammatory bowel disease and bacterial-epithelial interactions, and Dr Kevin Rioux (PhD, MD) will assess the impact of acetylsalicylic acid and the normal flora in inflammatory bowel disease. Having seen this programme enter its second year and the quality of the applications it attracts, it is our hope to sustain this fledgling programme. It is a pleasure to be able to thank the Crohn's and Colitis Foundation of Canada (CCFC) and AstraZeneca Canada Inc for the continued funding of this research initiative.

\section{CAG-CIHR-Partner Funded Post-Doctoral Operating Fellowship Programme}

The fellowship programme is the hallmark of excellence in the CAG research activities. Recently, Sandra Daniels and I summarized and published an article (Can J Gastroenterol 2003;17:437-9) on the investment in and resultant productivity from the first 10 years of the fellowship programme. The data are remarkable and testify to an outstanding programme - a reflection of the value that the CAG executive and CAG partners place on this programme and the quality of the fellows who receive support. The report was further distributed to the Canadian public in an excellent insert that appeared in the December 29, 2003 issue of Maclean's and the February issue of L'actualité.

This year, 26 fellowship applications were received. With support from CIHR, the CCFC, the CDHF and the CAG's industrial partners (see acknowledgements) 14 fellowships were funded - a $54 \%$ success rate (comparable with last year's 56\% success rate). Ten of 15 applications from $\mathrm{PhD}$ scientists were funded and four of 11 from MD scientists. Twelve of 22 male applicants were funded (ie, 55\%) and two of four female applicants (50\%) were successful in this competition (Table 3 ).

\section{PhD studentships}

In the past year, five CAG trainee members received one-year studentships $(\$ 20,500)$ in a partnered programme with CIHR and CDHF. Applications for the 2004-2005 academic year are currently reviewed by CIHR. Four awards will be made in partnership with CDHF, Ferring Pharmaceuticals and AstraZeneca Canada Inc.
Abbott Laboratories Ltd. 
Table 1

The Canadian Association of Gastroenterology Research Committee (2004)

\begin{tabular}{llc}
\hline Member & \multicolumn{1}{c}{ Institution } & Term \\
\hline Derek M McKay (PhD) (Chair) & McMaster University, Hamilton, Ontario & $2002-2005$ \\
Alison Fox-Robichaud (MD) & McMaster University, Hamilton, Ontario & $2004-2007$ \\
Linda Rabeneck (MD) & University of Toronto, Toronto, Ontario & $2004-2007$ \\
Nathalie Rivard (PhD) & Sherbrooke University, Sherbrooke, Quebec & $2004-2007$ \\
Andre Buret (PhD) & University of Calgary, Calgary, Alberta & $2004-2007$ \\
Jon Meddings (MD) & University of Calgary, Calgary, Alberta & $2003-2006$ \\
Andrew Stadnyk (PhD) & Dalhousie University, Halifax, Nova Scotia & $2003-2006$ \\
David Armstrong (MD) & McMaster University, Hamilton, Ontario & $2002-2005$ \\
Marc Deschenes (MD) & McGill University, Montreal, Quebec & $2002-2005$ \\
Johane Allard (MD) & University of Toronto, Toronto, Ontario & $2002-2005$ \\
Linda Yu (PhD)* & University of Calgary, Calgary, Alberta & $2003-2005$ \\
Stephen Vanner (MD) &
\end{tabular}

${ }^{*}$ Postdoctoral fellow representative; ${ }^{\dagger}$ Representative of Canadian Digestive Health Foundation

\section{Table 2}

Successful applicants in the Fellow-to-Faculty Transition Award 2004 Competition

\begin{tabular}{llc}
\hline Fellow & \multicolumn{1}{c}{ Partner } & \multicolumn{1}{c}{ Institution } \\
\hline E Ambrose & AstraZeneca Canada Inc & University of Calgary, Calgary, Alberta \\
K Rioux & Crohn's and Colitis Foundation of Canada & University of Alberta, Edmonton, Alberta \\
\hline
\end{tabular}

\section{CAG summer studentships}

It is critical that young investigators be supported at all levels of their training. Thus, in partnership with CCFC, eight students received awards (salary plus a small operating budget; $\$ 5,000$ /award) to work in laboratories of established investigators whose interests cover many facets of gut function (Table 4). Twenty high quality applications were reviewed, giving a $40 \%$ success rate in this year's competition.

\section{Resident Research Programme - A NEW INITIATIVE}

We recognized that one particular constituent of the CAG membership was being overlooked - the GI resident. To address this, and with support from ALTANA Pharma Inc, we are pleased to announce the GI Residents Research Programme Competition. Four residents will receive up to $\$ 5,000$ each to conduct a research project in the 2004-2005 academic year (beginning July 1, 2004) under the supervision of a CAG member in good standing (application information can be found at www.cag-acg.org). It is our goal to maintain this programme in future years.

\section{Awardees}

Congratulations to all the successful awardees. Well done! We look forward to the results of your labours and your continued participation in Canadian GI research and CAG activities. And again, many thanks to CIHR and the CAG partners - the eight summer studentships, 14 fellowships, two transition awards and two grants add up to a research dollar commitment in 2004 of $\$ 2,504,000$. Simply outstanding!

\section{Canadian Digestive Disease Week 2004}

The other major role of the Research Committee is the organization of the Canadian Digestive Disease Week (CDDW) which showcases the Canadian GI research community. Approximately 230 abstracts were submitted to the core scientific programme and 178 of these were accepted for presentation, 18 as oral presentations and the remainder in one of two poster sessions. Based on the previous year's needs assessment of the CAG membership, scientific symposia were presented on: colorectal cancer (chaired by Drs J Allard [University of Toronto] and Y-I Kim [University of Toronto]) and inflammatory bowel disease (chaired by Drs A Stadnyk [Dalhousie University] and L Yu [University of Calgary]). A workshop entitled "Transition from trainee-to-faculty" was organized and chaired by Drs K Chadee (McGill University) and D McKay (McMaster University), in which sessions on obstacles facing young faculty, grant writing and sources of nongovernment research funding were presented.

The following are the 2004 recipients of CAG awards:

- Dr Jonathan Meddings (University of Calgary) Research Excellence Award;

- Dr Nathalie Vergnolle (University of Calgary) - Young Investigator Award;

- Dr Sander van Zanten (Dalhousie University) - Visiting Professor;

- Dr Ivan Beck (Queen's University) - Education Excellence Award Lecturer;

- Dr Norman Marcon (University of Toronto) Distinguished Service Award;

- Dr Nicholas Diamant (University of Toronto) Distinguished Service Award; and

- Dr W Allan Walker (Harvard University) - The R.D. McKenna Memorial Lecture.

This year's student research prizes, based on the quality of submitted abstracts to CDDW 2004, were awarded to: Ms N Ramji (Queen's University), Ms M Gareau (McMaster University), 
Table 3

CAG-CIHR-Partner Funded Post-Doctoral Fellowships (July 2004)

\begin{tabular}{llllr}
\hline Candidate & Industrial partner & Years & \multicolumn{1}{c}{ Institution } \\
\hline Ryuyo Suzuki & ALTANA Pharma Inc & 2 & University of Montreal, Montreal, Quebec & Supervisor \\
Andre Klein & AstraZeneca Canada Inc & $2(+1)$ & University of Calgary, Calgary, Alberta & E Seidman \\
Alan Lomax & AstraZeneca Canada Inc & $2(+1)$ & University of Calgary, Calgary, Alberta & J Wallace \\
Julian Guttman & AstraZeneca Canada Inc & $2(+1)$ & University of British Columbia, Vancouver, British Columbia \\
Kathryn Howe & AstraZeneca Canada Inc & $2(+1)$ & University of Toronto, Toronto, Ontario & B Finlay \\
Sung Jin Park & AstraZeneca Canada Inc & 2 & McMaster University, Hamilton, Ontario & P Sherman \\
Mauricio Terbiznik* & AstraZeneca Canada Inc & 2 & University of Toronto, Toronto, Ontario & K Muizinga \\
Indranil Dey & Axcan Pharma Inc & 2 & McGill University, Montreal, Quebec & W Jones \\
Hongying Wang & Axcan Pharma Inc & 2 & University of Calgary, Calgary, Alberta & K Chadee \\
Robert Penner & CCFC & $1(+1)$ & University of Alberta, Edmonton, Alberta & N Vergnolle \\
Nicolas Cenac & CCFC & $1(+1)$ & University of Calgary, Calgary, Alberta & B Finlay \\
Ohad Gal-Mor & Ferring Pharmaceuticals & 1 & University of British Columbia, Vancouver, British Columbia \\
Dan Comay & Pentax Precision & 2 & McGill University, Montreal, Quebec & A Barkun \\
Noel Peretti & Schstruments Corp & & & University of Montreal, Montreal, Quebec \\
Jason Szeto & Solvay Pharma Inc & 2 & University of Toronto, Toronto, Ontario & E Levy \\
\hline
\end{tabular}

*Transfer of award from previous fellow; ${ }^{\dagger}$ In association with the Canadian Association for the Study of the Liver. CAG Canadian Association of Gastroenterology; CCFC Crohn's and Colitis Foundation of Canada; CIHR Canadian Institutes of Health Research

Table 4

CAG-CCFC funded summer studentships (2004)

\begin{tabular}{lclr}
\hline Candidate & Sponsor & \multicolumn{1}{c}{ Institution } & Supervisor \\
\hline Katherine Matheson & CCFC & Dalhousie University, Halifax, Nova Scotia & A Stadnyk \\
Kristy Parker & CCFC & Queen's University, Kingston, Ontario & M Ropeleski \\
Adrienne Ma & CCFC & University of Calgary, Calgary, Alberta & D-M McCafferty \\
David Thiel & CCFC & University of Alberta, Edmonton, Alberta & N Diamant \\
David Reed & CAG & University of Toronto, Toronto, Ontario & N Jones \\
Diana Banks & CAG & University of Toronto, Toronto, Ontario & D McKay \\
Oren Steen & CCFC & McMaster University, Hamilton, Ontario & C Pin \\
Sami Chadi & CAG & University of Western Ontario, London, Ontario &
\end{tabular}

CAG Canadian Association of Gastroenterology; CCFC Crohn's and Colitis Foundation of Canada

Mr S Kammanadiminti (McGill University) and Mr C Reardon (McMaster University). These awards were sponsored by the CAG and the CCFC. Mr Michael Howorth, the National Director of the CCFC, presented awards to Ms Gareau and Ms Ramji.

\section{Workshops}

A formalized process for submission and review of workshop sponsorship has been approved by the CAG executive and is posted on the CAG Web site. Application deadlines are in March and September. Up to two workshops will be supported each year at a maximum value of $\$ 5,000$ each. This year, meetings hosted by Dr J Wallace (University of Calgary) and Dr K Croitoru (McMaster University) will be supported: "Nitric Oxide, Cytokines and Inflammation" (June 2004, Rio De Janeiro, Brazil) and "GI Response to Injury" (October 2004, Montebello, Quebec), respectively. Funds support CAG trainee member attendance at conferences.

Interactions with CIHR

This year, the presidents of the CAG and the CDHF, Dr P Sherman and Dr G Levy, signed a memorandum of under- standing (or collective agreement) with CIHR RxD. This document formalizes our partnership with CIHR and clearly defines the financial arrangements, review processes and policies surrounding partnered research programmes. The document is available from the CAG National Office. Basically, the document holds the CAG to CIHR review practices, standards and policies with additional criteria being added by the CAG. Stipulations are in place to allow updates and revisions to each part of the agreement and the memorandum of understanding will be reviewed in 2007 .

On behalf of the CAG and CDHF, myself and Dr S Vanner (Queen's University) responded to a call from Dr A Bernstein, the President of CIHR, for comments on the CIHR Blueprint, a strategic planning document. There was much of value in the Blueprint, although GI Research was not specifically mentioned. We drew this to Dr Bernstein's attention and highlighted the impact that digestive disease has on Canadians.

Research Topics III meeting

This trainee-oriented meeting was held in November 2003 at Taboo Resort, Gravenhurst, Ontario. Forty trainees, both basic science and clinical, were invited to give podium presentations 
and a mixture of eight established and junior faculty were invited to act as session chairs and mentors (see Can J Gastroenterol 2003;17:732-3). Feedback from the trainees was overwhelmingly positive and plans are underway for a similar event in October 2004. Financial support was provided by AstraZeneca Canada Inc and the scientific programme was reviewed by Drs G Greenberg (University of Toronto), K Croitoru and D McKay, with the CAG National Office coordinating the abstract submission, meeting management and event.

\section{The year ahead}

By any standards this has been an excellent year for highlighting Canadian GI research and everyone involved deserves congratulations. The goal for the CAG Research Committee is simply twofold: to consolidate and expand on this success. We will strive to maintain the level of excellence that already exists in our research programmes and will work to: fully establish the Fellow-to-Faculty and resident research programmes; expand the $\mathrm{PhD}$ studentship programme with the goal of achieving three-year awards; stimulate interactions between the GI community and other disciplines; foster closer relations with the CIHR Institute of Nutrition, Metabolism and Diabetes; and ensure that the CDDW is a first-rate gastroenterology research meeting with Canadian collegiality at the forefront.

Should CAG members have questions relating to the activities of the Research Committee or proposals on how to expand or promote our activities please contact me (mckayd@mcmaster.ca) or any member of the research committee (Table 1).

ACKNOWLEDGEMENTS: Funding for the 2004 year from the following partners is gratefully acknowledged: Canadian Institutes of Health Research, Abbott Laboratories Ltd, ALTANA Pharma Inc, AstraZeneca Canada Inc, Axcan Pharma Inc, Crohn's and Colitis Foundation of Canada, Canadian Digestive Health Foundation, Ferring Pharmaceuticals, Janssen-Ortho Inc, Pentax Precision Instruments Corp, Schering Canada Inc and Solvay Pharma Inc. 
CAG News 


\section{ERRATUM}

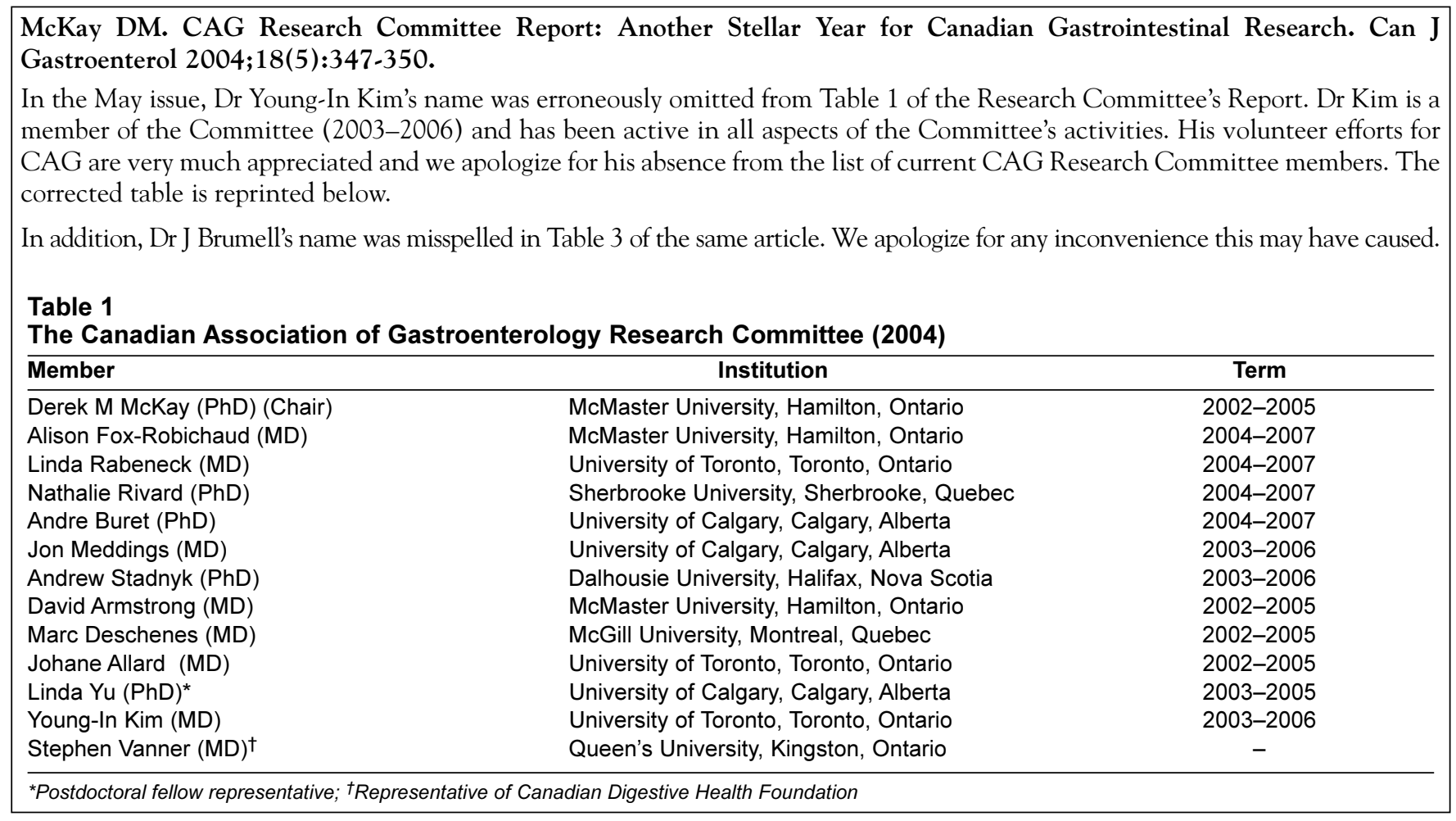




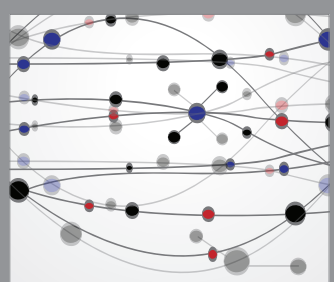

The Scientific World Journal
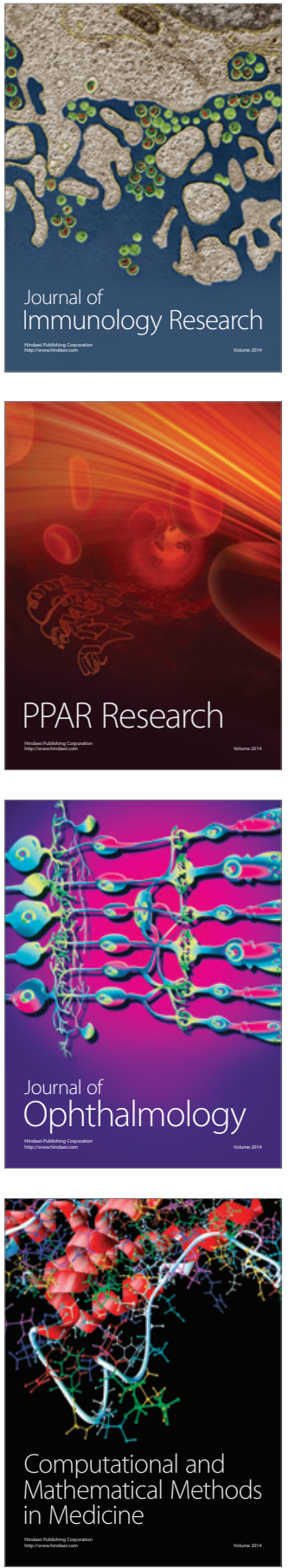

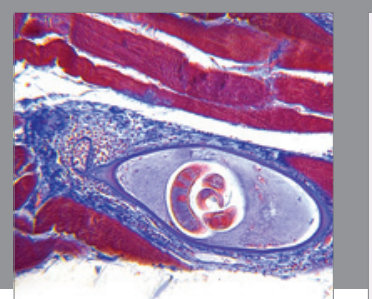

Gastroenterology Research and Practice

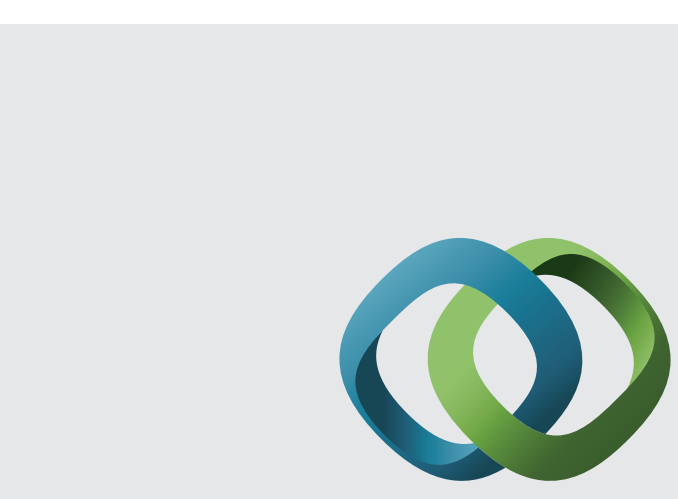

\section{Hindawi}

Submit your manuscripts at

http://www.hindawi.com
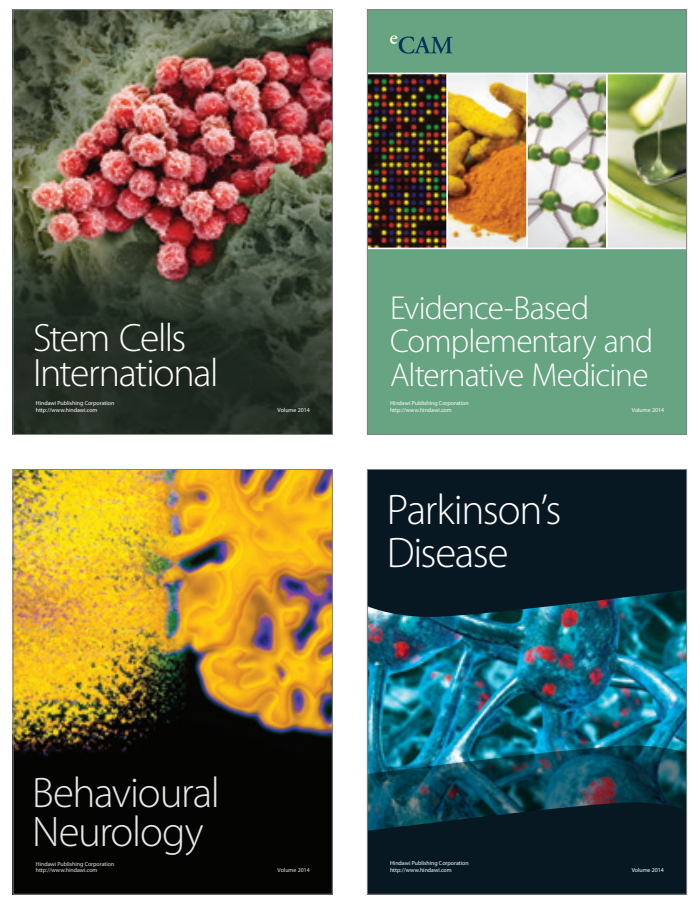
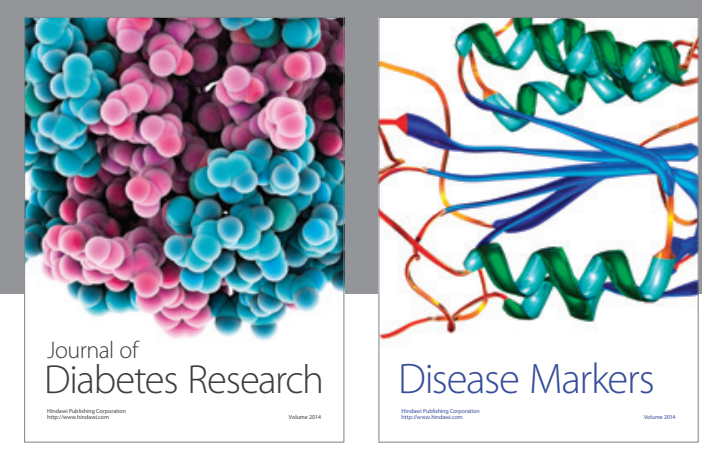

Disease Markers
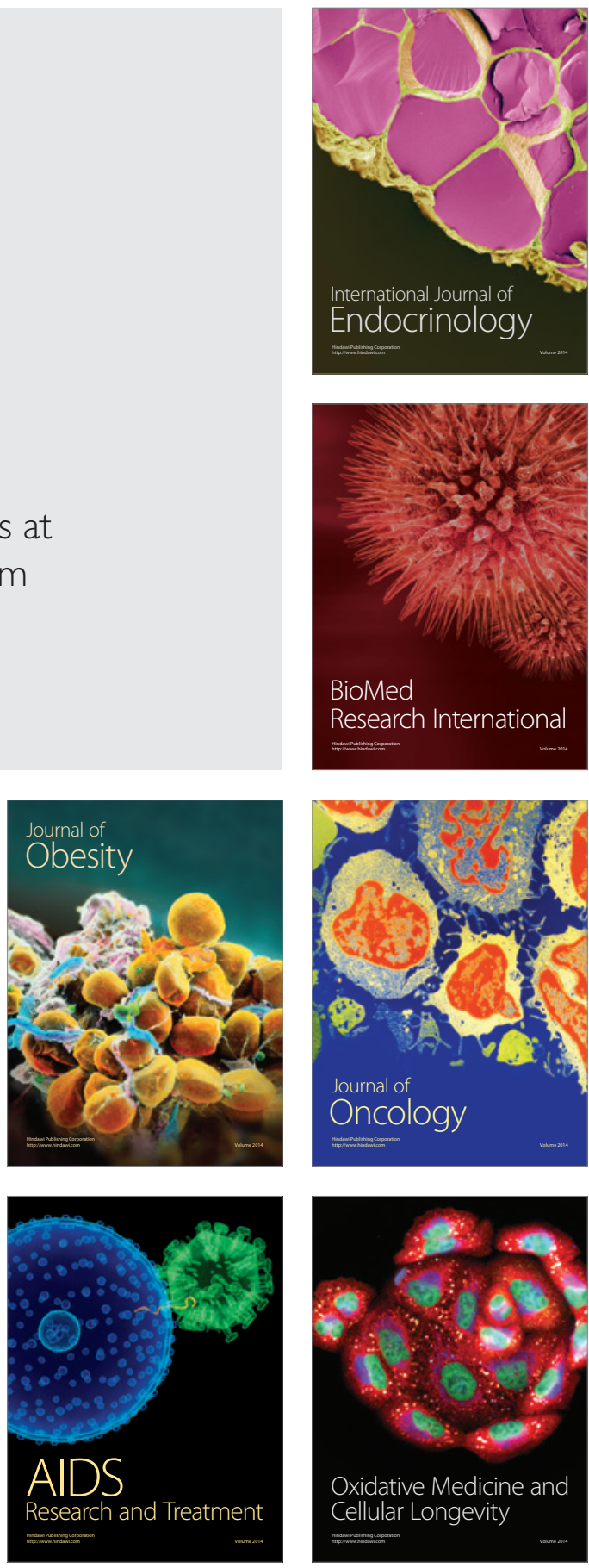